\title{
Drug-Induced Plasticity Contributing to Heightened Relapse Susceptibility: Neurochemical Changes and Augmented Reinstatement in High-Intake Rats
}

\author{
Aric Madayag, Kristen S. Kau, Doug Lobner, John R. Mantsch, Samantha Wisniewski, and David A. Baker \\ Department of Biomedical Sciences, Marquette University, Milwaukee, Wisconsin 53233
}

\begin{abstract}
A key in understanding the neurobiology of addiction and developing effective pharmacotherapies is revealing drug-induced plasticity that results in heightened relapse susceptibility. Previous studies have demonstrated that increased extracellular glutamate, but not dopamine, in the nucleus accumbens core (NAcc) is necessary for cocaine-induced reinstatement. In this report, we examined whether drug-induced adaptations that are necessary to generate cocaine-induced reinstatement also determine relapse vulnerability. To do this, rats were assigned to self-administer cocaine under conditions resulting in low ( $2 \mathrm{~h} / \mathrm{d} ; 0.5 \mathrm{mg} / \mathrm{kg} /$ infusion, i.v. $)$ or high $(6 \mathrm{~h} / \mathrm{d} ; 1.0$ $\mathrm{mg} / \mathrm{kg} /$ infusion, i.v.) levels of drug intake since these manipulations produce groups of rats exhibiting differences in the magnitude of cocaine-induced reinstatement. Approximately $19 \mathrm{~d}$ after the last session, cocaine-induced drug seeking and extracellular levels of glutamate and dopamine in the NAcc were measured. Contrary to our hypothesis, high-intake rats exhibited a more robust cocaineinduced increase in extracellular levels of dopamine but not glutamate. Further, increased reinstatement in high-intake rats was no longer observed when the $\mathrm{D}_{1}$ receptor antagonist $\mathrm{SCH}-23390$ was infused into the NAcc. The sensitized dopamine response to cocaine in high-intake rats may involve blunted cystine-glutamate exchange by system $\mathrm{x}_{\mathrm{c}^{-}}$. Reduced ${ }^{14} \mathrm{C}$-cystine uptake through system $\mathrm{x}_{\mathrm{c}^{-}}$was evident in NAcc tissue slices obtained from high-intake rats, and the augmented dopamine response in these rats was no longer observed when subjects received the cysteine prodrug $N$-acetyl cysteine. These data reveal a role for drug-induced NAcc dopamine in heightened relapse vulnerability observed in rats with a history of high levels of drug intake.
\end{abstract}

\section{Introduction}

Understanding addiction will require the identification of neuroplasticity underlying compulsive drug seeking and heightened relapse susceptibility. Toward this end, investigators commonly examine drug seeking in rodents using the reinstatement paradigm whereby the capacity of stimuli to reinstate extinguished responding on a lever that had previously been used to selfadminister the drug is assessed [for review, see Stewart (2000), Schmidt et al. (2005), and Epstein et al. (2006)]. In this model, extinguished drug seeking can be reinstated by stimuli that lead to relapse in humans: acute exposure to the previously used drug, drug-associated cues, and stress (Stewart, 1983; Meil and See, 1996; Shaham et al., 1996). Thus, drug-treated and drug-naive subjects are compared to reveal adaptations in drug-withdrawn rats that are necessary for stimuli to reinstate drug seeking; however, this approach may not reveal plasticity that underlies differences in relapse vulnerability among cocaine-withdrawn subjects. For example, increased levels of extracellular glutamate in the nucleus accumbens core (NAcc) are necessary for cocaine-induced rein-

Received March 19, 2009; revised Nov. 10, 2009; accepted Nov. 11, 2009

This work was supported by National Institute on Drug Abuse Grants DA017328 (D.B.), DA025617 (D.B.), and DA015758 (J.M.).

Correspondence should be addressed to Dr. David A. Baker, Department of Biomedical Sciences, Marquette University, Suite 426, 561 North 15th Street, Milwaukee, WI 53233. E-mail: david.baker@mu.edu.

D0I:10.1523/JNEUROSCI.1342-09.2010

Copyright $\odot 2010$ the authors $\quad 0270-6474 / 10 / 300210-08 \$ 15.00 / 0$ statement in rodents (Park et al., 2002; McFarland et al., 2003; Schmidt et al., 2005; Madayag et al., 2007), yet it is unknown whether changes in extracellular glutamate will predict differences in the magnitude of cocaine reinstatement. In contrast, dopamine receptor stimulation in the NAcc is not necessary for cocaine-induced reinstatement (Cornish and Kalivas, 2000; Anderson et al., 2003; Bachtell et al., 2005), yet it is possible that increased dopamine receptor stimulation would lead to increased drug seeking (Cornish and Kalivas, 2000; Bachtell et al., 2005) (although see Schmidt et al., 2006).

To isolate drug-induced plasticity that may underlie relapse vulnerability from other factors, such as genetic predisposition, experimenter-controlled manipulations impacting drug intake and seeking need to be used. Between-group differences in cocaine intake can be produced by varying self-administration parameters, such as dose and access conditions. Importantly, high-intake groups exhibit higher levels and a more compulsive pattern of drug seeking (Ahmed and Koob, 1998; Mantsch et al., 2004; Vanderschuren and Everitt, 2004; Ahmed and Cador, 2006; Kippin et al., 2006; Lenoir and Ahmed, 2007; Rogers et al., 2008).

We tested the hypothesis that high-intake rats exhibiting heightened relapse vulnerability would display a more robust cocaine-induced increase in extracellular glutamate, but not dopamine, in the NAcc. Next, we assessed intake-dependent changes in cystine-glutamate exchange from system $\mathrm{x}_{\mathrm{c}}$ - since this process can influence extracellular levels of dopamine or glutamate. Specifically, impaired cystine-glutamate exchange could result in 
increased synaptic release of glutamate or dopamine due to reduced activation of inhibitory group 2/3 metabotropic receptors (mGluR2/3) (Baskys and Malenka, 1991; Cochilla and Alford, 1998; Hu et al., 1999; Schoepp, 2001; Moran et al., 2005). In support, cocaine-withdrawn rats exhibit reduced cystine-glutamate exchange and mGluR2/3 function (Xi et al., 2002; Madayag et al., 2007), as well as a sensitized cocaine-evoked increase in extracellular glutamate in the NAcc relative to drug-naive subjects (Pierce et al., 1996; Reid and Berger, 1996). Thus, further impairment of cystine-glutamate exchange in high-intake rats may contribute to more pronounced disruptions in extracellular glutamate or dopamine relative to low-intake rats.

\section{Materials and Methods}

Animals. These experiments used male Sprague Dawley rats (Harlan) weighing 275-325 g upon arrival. Rats were individually housed in a temperature-controlled colony room with a $12 \mathrm{~h}$ reversed light/dark cycle. Housing conditions and experimental protocols were approved by the Marquette University Institutional Animal Care and Use Committee and performed according to the National Institutes of Health Guide for the Care and Use of Laboratory Animals (revised 1996).

Surgeries. Rats were implanted with indwelling catheters under ketamine $\mathrm{HCl}$ (100 mg/kg, i.p., Fort Dodge Animal Health) and xylazine (2 $\mathrm{mg} / \mathrm{kg}$, i.p., Lloyd Laboratories) anesthesia. A silicon tubing catheter (Dow Corning; $0.64 \mathrm{~mm}$ inner diameter; $1.19 \mathrm{~mm}$ outer diameter) was implanted such that it entered the jugular vein through the right posterior facial vein and terminated at the right atrium. The catheter was sutured to the vein at the entry point. The distal aspect of the catheter, which consisted of a 22-gauge guide cannula (Plastics One) attached with dental acrylic to a piece of polypropylene monofilament surgical mesh (Atrium Medical), exited $2 \mathrm{~cm}$ posterior to the scapulae. Throughout the experiment, catheters were filled daily with a heparin solution $(83 \mathrm{IU} / \mathrm{ml}$; Elkins-Sinn) and capped when disconnected from the leash/delivery line assembly. Rats were also implanted with indwelling bilateral guide cannulae (20 gauge, $14 \mathrm{~mm}$; Plastics One) using the following coordinates derived from Paxinos and Watson (1986): $+0.9 \mathrm{~mm}$ anterior, $\pm 2.5 \mathrm{~mm}$ mediolateral to bregma, and $-4.4 \mathrm{~mm}$ from the surface of the skull at a $6^{\circ}$ angle from vertical. The placement of the active region of the microdialysis probe, which began $1 \mathrm{~mm}$ beyond the ventral tip of the guide cannulae, was primarily in the NAcc although regions immediately dorsal and ventral to this were also likely sampled. Following surgery, rats were given at least $5 \mathrm{~d}$ to recover before testing. During this time, rats were provided acetaminophen $(480 \mathrm{mg} / \mathrm{L})$ in their drinking water and injected daily with a sterile cefazolin antibiotic solution (15 mg, i.v.; West-Ward Pharmaceutical).

Cocaine self-administration training. Self-administration occurred in operant conditioning chambers (ENV-008CT, MED-Associates) housed in sound attenuating cubicles (ENV-016M, MED-Associates) and equipped with two retractable levers, two stimulus lights, and a water bottle. At least $5 \mathrm{~d}$ after surgery, rats were food restricted with water available ad libitum; food restriction continued for the duration of the experiment (e.g., through reinstatement testing) and involved daily administration of $15 \mathrm{~g}$ of rat chow in the late afternoon or immediately following an operant session. Rats were then placed into the operant conditioning chambers overnight and responses on the lever designated as active resulted in the delivery of food pellets under a fixed ratio 1 schedule of reinforcement. Daily food training continued until subjects received at least 150 food rewards in a session, which typically occurred following the first session. During the acquisition phase of the experiment, all rats underwent drug self-administration training during daily $2 \mathrm{~h}$ sessions in which operant responses on the active lever were reinforced with an infusion of cocaine $(0.5 \mathrm{mg} / \mathrm{kg} / 200 \mu \mathrm{l}$, i.v., National Institute on Drug Abuse) under a fixed ratio 1 schedule of reinforcement. Each reinforced lever response resulted in the illumination of the stimulus light located above the active lever and was followed by a $25 \mathrm{~s} \mathrm{time-out}$ period. Responding on a second, inactive lever located on the back wall was recorded but had no programmed consequences. Acquisition of cocaine self-administration was operationally defined as $<10 \%$ variation in daily responding over at least three consecutive sessions. During the maintenance phase of the experiment, rats were assigned to selfadminister cocaine under low- $(0.5 \mathrm{mg} / \mathrm{kg} / 200 \mu$ l, i.v.; $2 \mathrm{~h} / \mathrm{d}$ for $11 \mathrm{~d})$ or high- $(1.0 \mathrm{mg} / \mathrm{kg} / 200 \mu$ l, i.v.; $6 \mathrm{~h} / \mathrm{d}$ for $11 \mathrm{~d})$ intake conditions.

Extinction/reinstatement testing. After completing 11 maintenance self-administration sessions, rats remained in their home cages for $7 \mathrm{~d}$ before extinction training. The $7 \mathrm{~d}$ delay was used to ensure an adequate drug-free period before reinstatement, even in rats that quickly extinguished responding. Extinction training involved placing rats into the operant conditioning chambers for $2 \mathrm{~h} / \mathrm{d}$ as described above except each active lever press now resulted in an infusion of saline. This continued until the mean number of lever presses was $\leq 10$ responses across at least three sessions, at which point rats were tested for drug-primed reinstatement. The reinstatement test day was identical to each extinction session except rats were injected with cocaine $(0-15 \mathrm{mg} / \mathrm{kg}$, i.p.). Because the mean number of extinction sessions needed to meet criteria $( \pm$ SEM) was $12.2 \pm 1.2$, reinstatement testing occurred $\sim 19 \mathrm{~d}$ after the last selfadministration session.

In vivo microdialysis testing. On the night before testing, microdialysis probes, constructed as previously described (Baker et al., 2003), were inserted into indwelling guide cannula. Rats were then housed overnight in the self-administration chambers. The next day, dialysis buffer $(5 \mathrm{mM}$ glucose, $140 \mathrm{~mm} \mathrm{NaCl}, 1.4 \mathrm{~mm} \mathrm{CaCl}_{2}, 1.2 \mathrm{~mm} \mathrm{MgCl}_{2}$, and $0.15 \% \mathrm{PBS}$, $\mathrm{pH}$ 7.4) was pumped through the probes at a rate of $1 \mu \mathrm{l} / \mathrm{min}$ for at least $3 \mathrm{~h}$ to permit an adequate period of time for neurotransmitter levels to stabilize. Afterward, 20 min samples were collected as described below for each experiment.

Quantification of glutamate. Glutamate concentrations were quantified by comparing peak heights from samples and external standards using HPLC coupled to fluorescence detection. Precolumn derivatization of glutamate with ophthaldehyde was performed using a Shimadzu LC10AD VP autosampler. The mobile phase consisted of $13 \%$ acetonitrile, $100 \mathrm{~mm} \mathrm{Na}_{2} \mathrm{HPO}_{4}$, and $0.1 \mathrm{~mm}$ EDTA, $\mathrm{pH}$ 5.90. Glutamate was separated using a reversed-phase column $(4 \mu \mathrm{M} ; 140 \times 6.0 \mathrm{~mm}$; Phenomenex), and detected using a Shimadzu 10RF-AXL fluorescence detector with an excitation and emission wavelength of 320 and $400 \mathrm{~nm}$.

Quantification of dopamine. Dopamine concentrations were quantified by comparing peak heights from samples and external standards using HPLC coupled to electrochemical detection. The mobile phase consisted of $15 \%$ acetonitrile, $10 \%$ methanol, $150 \mathrm{~mm} \mathrm{NaH}_{2} \mathrm{PO}_{4}, 4.76$ $\mathrm{mm}$ citric acid, $3 \mathrm{~mm}$ SDS, and $50 \mu \mathrm{m}$ EDTA, pH 5.6. Dopamine was separated using a reversed-phase column $(3 \mu \mathrm{m} ; 80 \times 3.2 \mathrm{~mm}$; ESA $)$ and detected using an ESA Coulochem II detector coupled to two electrodes set at $-0.075 \mathrm{~V}$ and $+0.25 \mathrm{~V}$, respectively.

Histology. Rats included in the microdialysis studies were given an overdose of pentobarbital ( $60 \mathrm{mg} / \mathrm{kg}$, i.p. $)$, and the brains were fixed by intracardiac infusion of $0.9 \%$ saline followed by $2.5 \%$ formalin solution. Brains were removed and stored in $2.5 \%$ formalin for at least $7 \mathrm{~d}$ before sectioning. The tissue was then blocked and coronal sections $(100 \mu \mathrm{M})$ were cut and stained with cresyl violet to verify probe placements.

$\left[{ }^{14} \mathrm{C}\right]$ Cystine uptake. Rats were decapitated and the brains were rapidly extracted and cut into $2 \mathrm{~mm}$ coronal slices using a brain matrix. Tissue punches (1.25 mm diameter, Stoelting) were collected from the NAcc and incubated at $37^{\circ} \mathrm{C}$ for $\sim 30 \mathrm{~min}$ on a nylon bolting cloth platform, submerged beneath $2 \mathrm{~mm}$ of standard buffer (Lobner and Lipton, 1993); the standard buffer contained $124 \mathrm{~mm} \mathrm{NaCl}, 3.0 \mathrm{~mm} \mathrm{KCl}, 1.4 \mathrm{~mm}$ $\mathrm{KH}_{2} \mathrm{PO}_{4}, 1.3 \mathrm{~mm} \mathrm{MgSO}_{4}, 26 \mathrm{~mm} \mathrm{NaHCO}, 2.4 \mathrm{~mm} \mathrm{CaCl}_{2}$, and $4 \mathrm{~mm}$ glucose, equilibrated with $95 \% \mathrm{O}_{2}, 5 \% \mathrm{CO}_{2} ; \mathrm{pH}$ was 7.4 . After a $30 \mathrm{~min}$ wash, the tissue was incubated for $30 \mathrm{~min}$ in standard buffer containing ${ }^{14} \mathrm{C}$-cystine $(0.03 \mu \mathrm{Ci} / \mathrm{ml}$; PerkinElmer $)$. D-Aspartate $(1 \mathrm{~mm})$ was also added to the incubation buffer to prevent uptake via $\mathrm{X}_{\mathrm{AG}}$. After $30 \mathrm{~min}$ incubation, the tissue punches were washed four times in ice-cold standard buffer and dissolved in $250 \mu \mathrm{l}$ of 1\% SDS. One aliquot (100 $\mu \mathrm{l})$ was used to measure ${ }^{14} \mathrm{C}$-cystine uptake by scintillation counting; a second aliquot $(100 \mu \mathrm{l})$ was used to assess protein content by the BCA method. Additional punches from each subject were processed as described above with the exception that unlabeled (S)-4-carboxyphenylglycine (1 mM) was added $10 \mathrm{~min}$ prior and for the duration of the $30 \mathrm{~min}$ incubation with ${ }^{14} \mathrm{C}$-cystine $(0.03 \mu \mathrm{Ci} / \mathrm{ml})$. These values reflect labeling indepen- 
dent of system $\mathrm{x}_{\mathrm{c}}{ }^{-}$and were subtracted from the total labeling obtained from each subject to get a measure that solely reflected uptake through cystine-glutamate exchange.

Experiment 1: impact of intake conditions on cocaine-primed reinstatement. Access conditions and dose of cocaine during 11 maintenance sessions of self-administration training were manipulated to isolate the contribution of drug-induced plasticity to group differences in the magnitude of reinstatement. Following acquisition training, rats were assigned to self-administer cocaine under low- $(0.5 \mathrm{mg} / \mathrm{kg} / 200 \mu$ l, i.v.; 2 h/d) or high- $(1.0 \mathrm{mg} / \mathrm{kg} / 200 \mu$ l, i.v.; $6 \mathrm{~h} / \mathrm{d})$ intake conditions for 11 daily sessions. Assignment into the groups was done by matching drug intake across all acquisition sessions (low-intake assigned rats: $95 \pm 22.6 \mathrm{mg} / \mathrm{kg}$; high-intake assigned rats: $\left.109 \pm 12.98 \mathrm{mg} / \mathrm{kg} ; t_{(34)}=0.58, p>0.05\right)$. Following extinction (described above), rats were tested for reinstatement following an injection of cocaine $(0-15 \mathrm{mg} / \mathrm{kg}$, i.p.). Rats received 1-2 injections of cocaine with the order of dose balanced when multiple reinstatement tests were conducted.

Experiment 2: impact of intake conditions on cocaine-induced increases in extracellular glutamate and dopamine in the NAcc. Increased extracellular glutamate is required for cocaine-primed reinstatement (Pierce et al., 1996; McFarland et al., 2003; Kalivas et al., 2005; Madayag et al., 2007). Rats that had self-administered cocaine under low- or high-intake conditions and completed extinction training underwent microdialysis testing. Twenty minute samples were collected for 100 before an injection of cocaine $(10 \mathrm{mg} / \mathrm{kg}$, i.p.). Afterward, microdialysis samples were collected and responding on the active lever was measured for the next 120 min. Samples were frozen at $-80^{\circ} \mathrm{C}$ until assayed for glutamate content. Additional rats were later run using an identical protocol to permit assessment of cocaine-induced changes in the levels of extracellular dopamine between low- and high-intake rats.

Experiment 3: impact of $D_{1}$ receptor blockade on cocaine-induced reinstatement by low- and high-intake rats. To examine the relevance of elevated levels of extracellular dopamine to augmented cocaine-induced reinstatement observed in high-intake rats, we examined reinstatement by low- and high-intake rats in the presence or absence of $D_{1}$-like dopamine receptor blockade. Rats were permitted to self-administer cocaine under low- $(0.5 \mathrm{mg} / \mathrm{kg} / 200 \mu$ l, i.v.; $2 \mathrm{~h} / \mathrm{d})$ or high- $(1.0 \mathrm{mg} / \mathrm{kg} / 200 \mu$ l, i.v.; $6 \mathrm{~h} / \mathrm{d})$ intake conditions. After extinction training, rats were implanted with removable microdialysis probes. The next day, rats were tested for cocaine-induced reinstatement as described above with the exception that 0 or $10 \mu \mathrm{M}$ of the $\mathrm{D}_{1}$-like dopamine receptor antagonist SCH-23390 [for dose justification, see Consolo et al. (1999) and West and Grace (2002)] was infused into the NAcc via reverse dialysis beginning $1 \mathrm{~h}$ before the cocaine injection and continuing for the duration of the experiment.

To determine whether the concentration of SCH-23390 used in the present study produces a general deficit in operant responding, the impact of SCH-23390 infused into the NAcc on operant responding for sucrose pellets was examined in drug-naive subjects. Briefly, rats were implanted with bilateral guide cannula as described above. After at least 5 recovery days, rats were placed in the operant conditioning chambers used in the above experiments. Operant responses on the active lever were reinforced with the delivery of sucrose pellets under a fixed ratio 1 schedule of reinforcement during daily $45 \mathrm{~min}$ sessions. Once responding stabilized ( $<20 \%$ variance over five sessions), rats underwent an additional session that also involved a mock dialysis test. Specifically, removable microdialysis probes that did not extend beyond the guide cannula were inserted and secured before the session. The next day, a final session was conducted in which removable microdialysis probes were inserted into the NAcc and SCH-23390 $(10 \mu \mathrm{M})$ was infused for $1 \mathrm{~h}$ before the beginning of the session.

Experiment 4: system $x_{c}$-activity in low- and high-intake rats. Cystineglutamate exchange has been shown to contribute to cocaine-primed reinstatement and is capable of regulating extracellular levels of dopamine and glutamate in the NAcc (Baker et al., 2003; Moran et al., 2005; Madayag et al., 2007); thus, an abnormal neurochemical profile in highintake rats may be due to drug-induced changes in system $\mathrm{x}_{\mathrm{c}}{ }^{-}$activity relative to low-intake rats. To explore this, ${ }^{14} \mathrm{C}$-cystine uptake restricted to system $\mathrm{x}_{\mathrm{c}}-$ was assessed in NAcc tissue punches obtained 2-3 weeks after the last session of cocaine self-administration under low- $(0.5 \mathrm{mg} /$ $\mathrm{kg} / 200 \mu$ l, i.v.; $2 \mathrm{~h} / \mathrm{d})$ or high- $(1.0 \mathrm{mg} / \mathrm{kg} / 200 \mu$ l, i.v.; $6 \mathrm{~h} / \mathrm{d})$ intake conditions.

To test the hypothesis that increased cystine-glutamate exchange by system $\mathrm{x}_{\mathrm{c}}$ - would reverse the neurochemical differences between lowand high-intake rats, we then examined the impact of the cysteine prodrug $\mathrm{N}$-acetyl cysteine on cocaine-induced increases in extracellular dopamine in the NAcc. Rats were permitted to self-administer cocaine under low- $(0.5 \mathrm{mg} / \mathrm{kg} / 200 \mu$ l, i.v.; $2 \mathrm{~h} / \mathrm{d})$ or high- $(1.0 \mathrm{mg} / \mathrm{kg} / 200 \mu$ l, i.v.; $6 \mathrm{~h} / \mathrm{d}$ ) intake conditions for 11 daily sessions. Following daily extinction testing, rats underwent microdialysis testing in the presence or absence of $\mathrm{N}$-acetyl cysteine. On this day, basal samples were collected for $100 \mathrm{~min}$ as described above. Afterward, rats received an injection of $\mathrm{N}$-acetyl cysteine $(0$ or $60 \mathrm{mg} / \mathrm{kg}$, i.p. ) and samples were collected for an additional 60 $\mathrm{min}$. Last, rats received an injection of cocaine $(10 \mathrm{mg} / \mathrm{kg}$, i.p.); microdialysis samples were then collected and responding on the active lever was measured for the next $120 \mathrm{~min}$ as described above. Samples were frozen at $-80^{\circ} \mathrm{C}$ until assayed for dopamine content.

Statistical analyses. SPSS software (version 16) was used to perform the statistical analyses. Data were analyzed using ANOVA with selfadministration access conditions, $\mathrm{N}$-acetyl cysteine dose, or SCH-23390 concentration as potential between-subject factors and time (day or 20 min interval) as a repeated factor. Post hoc comparisons were conducted using $t$ tests when only two data points were compared or Fisher LSD when the comparison involved more than two data points. Note, the $p$ value required for significance in the post hoc tests are adjusted downward by the total number of comparisons conducted to control for $\alpha$ inflation.

\section{Results}

\section{Experiment 1: impact of intake conditions on} cocaine-primed reinstatement

Varying self-administration parameters, including dose and access period, produces significant group differences in cocaine intake (mean mg/kg per 12 maintenance self-administration sessions \pm SEM: low-intake rats $135 \pm 9$; high-intake rats $699 \pm 39$; $t$ test: $\left.t_{(34)}=12.99, p<0.001\right)$. Figure $1 a$ illustrates responding during the first four extinction sessions; note that only four sessions are depicted because some rats met the extinction criteria before the fifth session. An ANOVA comparing extinction responding with intake as a between-subjects variable and time (four sessions) as a within-subjects variable failed to demonstrate a significant effect (interaction: $F_{(3,102)}=1.01, p=0.393$; main effect: $\left.F_{(1,34)}=0.435, p=0.514\right)$ of intake conditions. Additionally, low- (mean number of sessions \pm SEM: $10.9 \pm 1.1$ ) and high- $(13.4 \pm 1.5)$ intake rats required a similar number of extinction sessions to reach the extinction criteria $\left(t_{(34)}=1.38, p=\right.$ 0.183 ; data not shown). Figure $1 b$ depicts responding following an injection of cocaine $(0-15 \mathrm{mg} / \mathrm{kg}$, i.p.). An ANOVA with cocaine dose on the test day and intake conditions during selfadministration as between-subjects variables yielded a significant interaction $\left(F_{(3,56)}=2.81, p=0.047\right)$. Subsequent post hoc comparisons indicated that low- and high-intake rats displayed reinstatement when administered cocaine at doses of 10 and 15 $\mathrm{mg} / \mathrm{kg}$ (i.p.), and this was evident as a significant increase in responding relative to the $0 \mathrm{mg} / \mathrm{kg}$ cocaine group (Fisher LSD, $p<0.0125$ ). The magnitude of reinstatement was significantly elevated in the high-intake group relative to the low-intake rats when each group received $10 \mathrm{mg} / \mathrm{kg}$ cocaine (i.p.; $t$ test, $t_{(21)}=$ 3.52, $p=0.002)$. Moreover, there was a significant correlation between cocaine intake during self-administration training and reinstatement magnitude at this dose $\left(r^{2}=0.497, p<0.001\right)$. As a result, the remaining studies involving cocaine administration used this dose. 


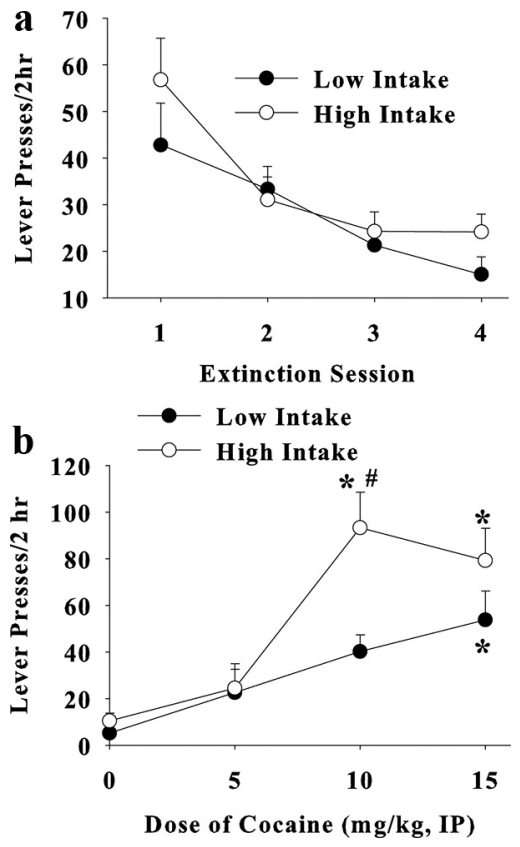

Figure 1. Data depict the mean number ( $\pm S E M)$ of responses during the first four extinction sessions $(\boldsymbol{a})$ or the test for cocaine-induced reinstatement $(\boldsymbol{b})$. Rats were assigned to selfadminister cocaine under low- $(0.5 \mathrm{mg} / \mathrm{kg} / 200 \mu$ l, i.v.; $2 \mathrm{~h} / \mathrm{d})$ or high- $(1.0 \mathrm{mg} / \mathrm{kg} / 200 \mu$ l, i.v.; $6 \mathrm{~h} / \mathrm{d}$ ) intake conditions. Seven days after the last self-administration session, rats underwent daily extinction training in the absence of any drug treatment. This was followed by a test for cocaine-induced reinstatement $(0,5,10$, or $15 \mathrm{mg} / \mathrm{kg}$, i.p.; for low-intake animals, $N=7,5,14$, and 6, respectively; for high-intake animals, $N=8,8,9$, and 7, respectively). ${ }^{*}$ Significant difference from the 0 cocaine group (Fisher LSD, $p<0.0125$ ). "Significant difference from the low-intake group receiving $10 \mathrm{mg} / \mathrm{kg}$ cocaine ( $t$ test, $p<0.0125)$.

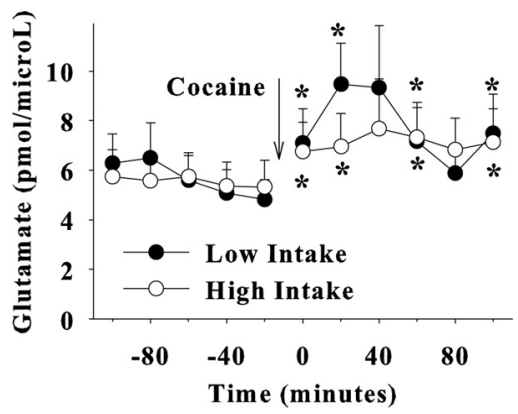

Figure 2. Extracellular glutamate levels in the nucleus accumbens core in low- and highintake rats presented as picomoles per microliter. Rats were assigned to self-administer cocaine under low- $(0.5 \mathrm{mg} / \mathrm{kg} / 200 \mu$ l, i.v.; $2 \mathrm{~h} / \mathrm{d} ; N=18)$ or high- $(1.0 \mathrm{mg} / \mathrm{kg} / 200 \mu \mathrm{l}$, i.v.; $6 \mathrm{~h} / \mathrm{d} ; N=19$ ) intake conditions over 11 daily sessions. Seven days after the last self-administration session, rats underwent daily extinction training in the absence of any drug treatment. Microdialysis was then used to sample extracellular glutamate in the nucleus accumbens core before and after a cocaine injection ( $10 \mathrm{mg} / \mathrm{kg}$, i.p.). *Significant difference from the last baseline sample (Fisher LSD, $p<0.0083$ ).

Experiment 2: impact of intake conditions on cocaine-induced increases in extracellular glutamate and dopamine in the NAcc Figure 2 illustrates extracellular glutamate levels in the NAcc before and after a cocaine injection $(10 \mathrm{mg} / \mathrm{kg}$, i.p.) in high- and low-intake rats when tested $\sim 3$ weeks after the last session of cocaine self-administration. As expected, the high-intake group in this microdialysis study exhibited augmented reinstatement relative to low-intake rats (mean lever presses \pm SEM, low-intake: $30.35 \pm 6.05$, high-intake: $86.89 \pm 10.86$; $t_{(33)}=4.476, p<$ $0.001)$. An ANOVA with intake conditions as a between-subjects factor and time (20 min samples) as a repeated measures factor

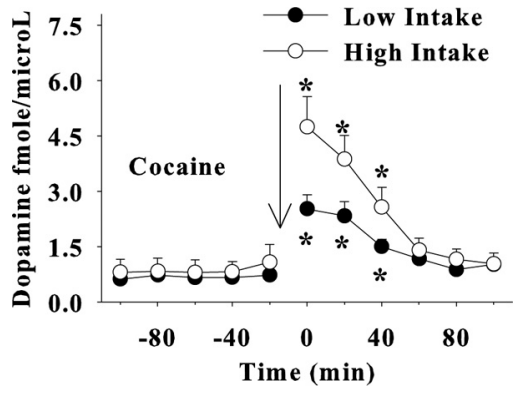

Figure 3. Extracellular dopamine levels in the nucleus accumbens core presented as femtomoles per microliter. Rats were assigned to self-administer cocaine under low- $(0.5 \mathrm{mg} / \mathrm{kg} / 200$ $\mu$ l, i.v.; $2 \mathrm{~h} / \mathrm{d} ; N=13)$ or high- $(1.0 \mathrm{mg} / \mathrm{kg} / 200 \mu$ l, i.v.; $6 \mathrm{~h} / \mathrm{d} ; N=12)$ intake conditions over 11 daily sessions. Seven days after the last self-administration session, rats underwent daily extinction training in the absence of any drug treatment. Microdialysis was then used to sample extracellular dopamine in the nucleus accumbens core before and after a cocaine injection (10 $\mathrm{mg} / \mathrm{kg}$, i.p.). ${ }^{*}$ Significant difference from the last baseline sample (Fisher $\mathrm{LSD}, p<0.0083$ ).

produced a significant effect of time $\left(F_{(10,350)}=4.32, p<0.001\right)$, in the absence of a significant main effect of intake $\left(F_{(1,35)}=0.101\right.$, $p=0.752)$ or an interaction between the variables $\left(F_{(10,350)}=0.773\right.$, $p=0.655)$. Post hoc comparisons indicated that there was a significant increase in extracellular glutamate levels in three of the samples collected after the cocaine injection regardless of intake conditions (Fisher LSD, $p<0.008$ ) (Fig. 2). An equivalent cocaine-induced glutamate response was also evident when areas under the curve (AUCs) were calculated using all of the postinjection samples and compared across intake conditions (mean AUC after cocaine \pm SEM: low intake $782 \pm 138$; high intake $\left.714 \pm 133 ; t_{(35)}=0.5, p=0.691\right)$.

Figure 3 illustrates extracellular dopamine levels in the NAcc before and after a cocaine injection $(10 \mathrm{mg} / \mathrm{kg}$, i.p.) in high- and low-intake rats when tested $\sim 3$ weeks after the last session of cocaine self-administration. As expected, the high-intake group in this microdialysis study exhibited augmented reinstatement relative to low-intake rats (mean lever presses \pm SEM, low-intake: $36.68 \pm 4.78$, high-intake: $91.33 \pm 9.69 ; t_{(32)}=5.689, p<$ 0.001). Surprisingly, an ANOVA with intake conditions as a between-subjects factor and time (20 min samples) as a repeated measure yielded a significant interaction $\left(F_{(10,230)}=4.14, p<\right.$ $0.001)$. An augmented cocaine-induced increase in extracellular dopamine was evident in high-intake rats when areas under the curve were calculated using all of the postinjection samples and compared across intake conditions (mean AUC after cocaine \pm SEM: low intake $153 \pm 21$; high intake $238 \pm 34 ; t_{(23)}=2.143$, $p=0.043)$.

Experiment 3: impact of $D_{1}$ receptor blockade on cocaine-induced reinstatement by low-and high-intake rats

Figure 4 depicts responding during extinction and reinstatement testing in rats when conducted in the absence (Fig. $4 a$ ) or presence of SCH-23390 (Fig. 4b) infused into the NAcc via reverse dialysis. An ANOVA with intake conditions and SCH-23390 concentration $(0$ or $10 \mu \mathrm{M})$ as between-subjects factors and experimental test phase (extinction, reinstatement) as a repeated measure yielded a three-way interaction $\left(F_{(1,31)}=16.99, p<\right.$ 0.001 ). Two separate ANOVAs (in the presence or absence of SCH-23390 infusion) were then conducted to deconstruct the three-way interaction with intake conditions as a betweensubjects variable and experimental phase as a repeated measure. In the absence of SCH-23390, a two-way interaction $\left(F_{(1,17)}=\right.$ 25.93, $p<0.001$ ) was obtained. Subsequent post hoc comparisons indicated that both intake groups exhibited significant reinstate- 


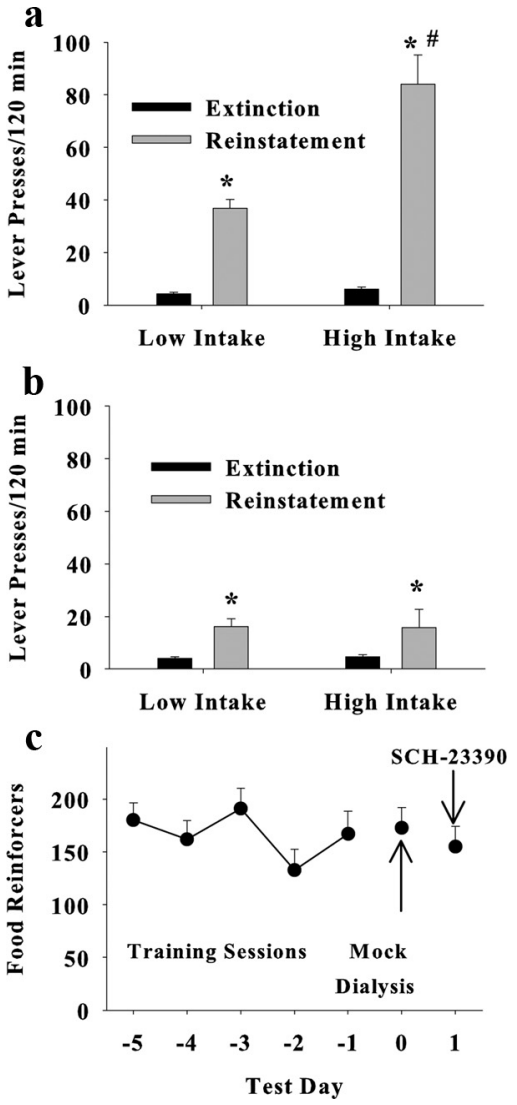

Figure 4. Data depict responding during extinction and cocaine reinstatement testing in the absence $(\boldsymbol{a})$ or presence $(\boldsymbol{b})$ of $\mathrm{SCH}-23390$. Rats self-administered cocaine under low- $(0.5$ $\mathrm{mg} / \mathrm{kg} / 200 \mu \mathrm{l}$, i.v.; $2 \mathrm{~h} / \mathrm{d} ; N=10-12 / \mathrm{group})$ or high- $(1.0 \mathrm{mg} / \mathrm{kg} / 200 \mu$ l, i.v.; $6 \mathrm{~h} / \mathrm{d} ; N=$ $6-7 /$ group) intake conditions over 11 daily sessions. Seven days after the last selfadministration session, rats underwent daily extinction training in the absence of any drug treatment. This was followed by a test for cocaine-induced $(10 \mathrm{mg} / \mathrm{kg}$, i.p.) reinstatement. Beginning $1 \mathrm{~h}$ before the injection of cocaine, $\mathrm{SCH}-23390$ ( 0 and $10 \mu \mathrm{m}$ ) was infused into the nucleus accumbens core via reverse dialysis for the duration of the experiment. c, Data depict the impact of SCH-23390 (10 $\mu \mathrm{m})$ infused into the nucleus accumbens core on operant responding reinforced by sucrose pellets in drug-naive subjects $(N=5)$. "Significant difference from low-intake rats ( $t$ test, $p<0.001)$. ${ }^{*}$ Significant difference from extinction responding $(\boldsymbol{a}, t$ test, $p<0.001 ; \boldsymbol{b}$, ANOVA main effect, $p<0.05$ ).

ment, and that the high-intake group exhibited higher levels of responding during the test for reinstatement relative to lowintake rats ( $t$ test, $p<0.0125)$. In the presence of SCH-23390, there was a main effect of experimental phase $\left(F_{(1,14)}=14.28, p=\right.$ $0.002)$, without a significant main effect of intake conditions $\left(F_{(1,14)}=0.002, p=0.965\right)$ or an interaction between the variables $\left(F_{(1,14)}=0.028, p=0.870\right)$.

To further characterize the reduction in responding, we then examined the impact of SCH-23390 infused into the NAcc on operant responding reinforced by sucrose pellets. Figure $4 c$ depicts the number of food reinforcers obtained during the last five training sessions, a mock dialysis session, or following reverse dialysis of SCH-23390. A one-way ANOVA with day as a repeated measure failed to produce a significant main effect of time $\left(F_{(6,24)}=2.16, p=0.083\right)$. Note, the variance contributing to the low $p$ value was due to the data obtained during the second training day. A $t$ test between the mock and test day yielded $t_{(8)}=$ $0.659, p=0.528$.

Experiment 4: system $x_{c}$-activity in low-and high-intake rats The mean counts/ $\mu$ g protein \pm SEM ${ }^{14} \mathrm{C}$-cystine uptake through system $\mathrm{x}_{\mathrm{c}}$ - in low- and high-intake rats was $109 \pm 7.2$ and $81.8 \pm$
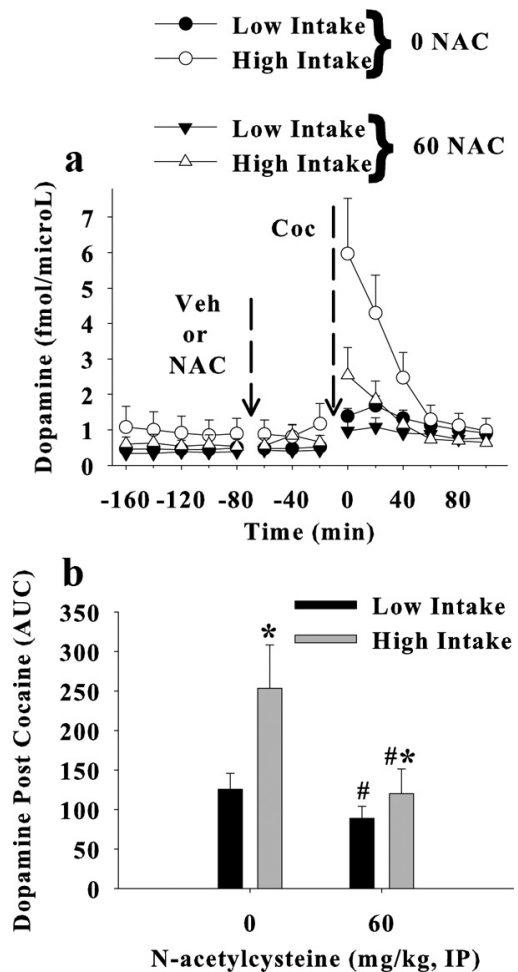

Figure 5. Extracellular dopamine in the nucleus accumbens core presented as femtomoles per microliter $(\boldsymbol{a})$ or AUC $(\boldsymbol{b})$ calculated from the samples collected following the cocaine injection. Rats were assigned to self-administer cocaine under low- $(0.5 \mathrm{mg} / \mathrm{kg} / 200 \mu$ l, i.v.; $2 \mathrm{~h} / \mathrm{d})$ or high- $(1.0 \mathrm{mg} / \mathrm{kg} / 200 \mu$ l, i.v.; $6 \mathrm{~h} / \mathrm{d})$ intake conditions over 11 daily sessions. Seven days after the last self-administration session, rats underwent daily extinction training in the absence of any drug treatment. Microdialysis was then used to sample extracellular dopamine in the nucleus accumbens core before and after injections of $\mathrm{N}$-acetyl cysteine ( $\mathrm{NAC} ; 0$ and $60 \mathrm{mg} / \mathrm{kg}$, i.p.; $N=7-11 /$ group) and cocaine (10 mg/kg, i.p.). " Significant difference from the $0 \mathrm{~N}$-acetyl cysteine group (ANOVA main effect, $p<0.05$ ). * Significant difference from low-intake rats (ANOVA main effect, $p<0.05$ ).

9.4, respectively. A $t$ test indicated that cystine-glutamate exchange in nucleus accumbens tissue punches was significantly reduced in high-intake rats relative to low-intake subjects $\left(t_{(7)}=\right.$ 2.36, $p=0.05$ ).

Figure $5 a$ illustrates extracellular dopamine levels in the NAcc before and after a cocaine injection in high- and low-intake rats when tested in the presence or absence of $N$-acetyl cysteine. An ANOVA with $N$-acetyl cysteine ( 0 or $60 \mathrm{mg} / \mathrm{kg}$, i.p.) and cocaine intake as between-subjects variables and time (before and after the cocaine injection) as a repeated measure yielded a significant interaction between $N$-acetyl cysteine and time $\left(F_{(13,429)}=2.93\right.$, $p<0.001)$, as well as an interaction between intake conditions and time $\left(F_{(13,429)}=6.5, p<0.001\right)$. Main effects of both $N$-acetyl cysteine $\left(F_{(13,247)}=3.125, p<0.001\right)$ and intake conditions $\left(F_{(13,247)}=3.125, p<0.001\right)$ were obtained when analyzing dopamine levels following the cocaine injection. Likewise, an ANOVA comparing dopamine levels (area under the curve) after a cocaine injection $(10 \mathrm{mg} / \mathrm{kg}$, i.p.) with $N$-acetyl cysteine $(0$ or 60 $\mathrm{mg} / \mathrm{kg}$, i.p.) and intake conditions as a between-subjects variable and time (20 min samples) as a repeated measure yielded a significant interaction $\left(F_{(13,247)}=3.125, p<0.001\right)$. Figure $5 b$ demonstrates that $\mathrm{N}$-acetyl cysteine significantly reduces the area under the curve calculated from dopamine content in samples collected after the cocaine injection relative to controls $\left(_{(19)}=\right.$ 2.148, $p=0.045)$. Figure 6 illustrates that the placement of the active region of the microdialysis probes (the ventral $2 \mathrm{~mm}$ of the 


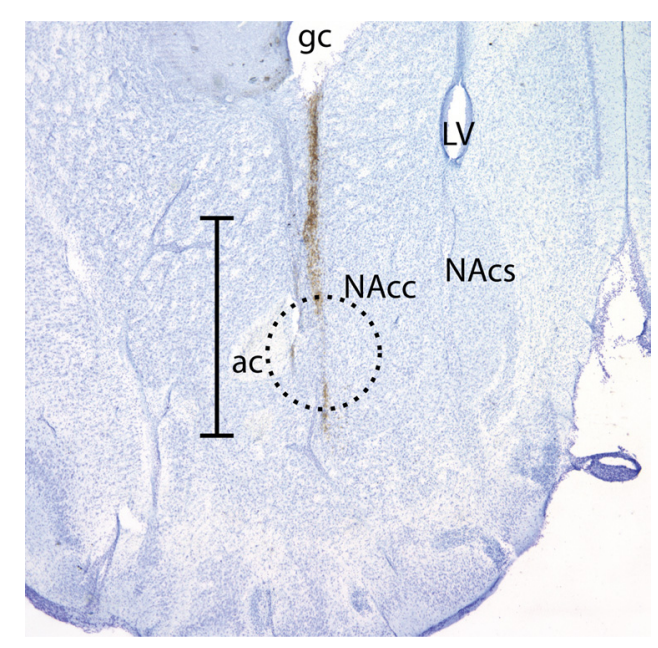

Figure 6. A representative coronal section illustrating the placement of microdialysis probes. The tract created extends $\sim 3 \mathrm{~mm}$ from the guide cannula with sampling only occurring from the most ventral $2 \mathrm{~mm}$ because this is the portion of the probe containing the dialysis membrane. The probes were primarily located in the nucleus accumbens core, although aspects of ventral nucleus accumbens shell and the striatum dorsal to the nucleus accumbens were likely sampled as well. The circle indicates the area sampled to generate tissue punches for assessment of ex vivo ${ }^{14} \mathrm{C}$-cystine transport via system $\mathrm{x}_{\mathrm{c}^{-}}$. Scale bar, $2 \mathrm{~mm}$. ac, Anterior commissure; LV, lateral ventricle; gc, guide cannula tract.

tract) in these studies is primarily in the NAcc, although aspects of the ventral nucleus accumbens shell (NAcs) and the striatum dorsal to the nucleus accumbens were likely sampled as well.

\section{Discussion}

Our goal was to determine whether adaptations necessary for cocaine-induced reinstatement also determine relapse vulnerability. Cocaine-induced increases in extracellular glutamate and dopamine in the NAcc were compared between rats assigned to self-administer cocaine under low- or high-intake conditions. This approach was used because reinstatement magnitude correlates with the amount of drug consumed (Sutton et al., 2000; Baker et al., 2001). Varying access and dose during self-administration training can result in significant group differences in drug intake and reinstatement (Ahmed and Koob, 1998; Mantsch et al., 2004; Ahmed and Cador, 2006; Kippin et al., 2006; Lenoir and Ahmed, 2007; Rogers et al., 2008) and a more compulsive pattern of drug-seeking (Vanderschuren and Everitt, 2004). Because differences in drug intake can be produced by experimentercontrolled manipulations, the contribution of drug-induced plasticity can be dissected from other factors that may contribute to relapse susceptibility.

\section{Augmented behavioral and neurochemical plasticity in high-intake rats}

Rats that self-administered cocaine under high-intake conditions, which included a higher cocaine dose $(1.0 \mathrm{mg} / \mathrm{kg})$ and increased access $(6 \mathrm{~h} / \mathrm{d})$ during maintenance self-administration sessions, exhibited increased cocaine-induced reinstatement relative to low-intake rats $(0.5 \mathrm{mg} / \mathrm{kg} ; 2 \mathrm{~h} / \mathrm{d})$. In contrast, there was no difference in extinction responding, which is inconsistent with an earlier report demonstrating reduced responding by longaccess rats during the first extinction session (Mantsch et al., 2004). A key difference is that a $7 \mathrm{~d}$ abstinence period between self-administration and extinction was included in our study to reduce the potential for high-cocaine intake to negatively impact behavior (e.g., "hangover" effect). Similar to cocaine reinstate- ment, high-intake rats display augmented drug seeking induced by an acute stressor (Ahmed et al., 2000; Mantsch et al., 2008) (although see Sorge and Stewart, 2005). Thus, increased drug seeking exhibited by high-intake rats may require a discrete stimulus (e.g., stress or drug).

We hypothesized that augmented reinstatement in highintake rats would be due, in part, to more pronounced changes involving extracellular glutamate in the NAcc since cocaineevoked increases in extracellular glutamate in the NAcc is necessary for cocaine-induced reinstatement (Park et al., 2002; Baker et al., 2003; McFarland et al., 2003; Schmidt et al., 2005; Madayag et al., 2007; Kau et al., 2008). Surprisingly, we found that low- and high-intake rats exhibited equivalent levels of extracellular glutamate before and after a cocaine injection, even though high-intake rats self-administered more cocaine and displayed augmented reinstatement. Although these data do not preclude the possibility that other aspects of excitatory signaling may be altered in high-intake rats (e.g., receptor expression), our results, at the very least, suggest that increased cocaine consumption does not result in more pronounced adaptations involving extracellular glutamate in the NAcc. More broadly, these data may indicate that a unique set of drug-induced adaptations emerges following high levels of drug intake that contribute to relapse vulnerability.

Unlike glutamate, high-intake rats exhibited a more robust cocaine-induced increase in extracellular dopamine in the NAcc relative to low-intake rats. This was unexpected since earlier studies failed to show an augmented dopaminergic response in high-intake rats (Ahmed et al., 2003; Lack et al., 2008). However, high-intake rats in our study self-administered more cocaine during training and received a higher dose of cocaine relative to rats in the Lack and Ahmed et al. studies, respectively. Thus, the sensitized dopamine response in the NAcc may represent drug-induced plasticity that only emerges following high levels of drug intake. Interestingly, a sensitized dopamine response in the striatum has been reported in human drug users, but only in subjects reporting a history of high levels of drug intake (Cox et al., 2009). This report was in contrast to earlier studies demonstrating that human cocaine abusers challenged with methamphetamine or amphetamine displayed a reduced dopaminergic response in the striatum (Volkow et al., 1997; Martinez et al., 2007). The presence or absence of drug-paired cues may be critical; Cox et al. (2009) suggest that a sensitized response requires the presence of drug-paired cues, which was not included in the earlier studies.

\section{$D_{1}$ dopamine receptor activation in the NAcc and heightened relapse}

We found that blockade of $\mathrm{D}_{1}$-like dopamine receptors in the NAcc reduced reinstatement in low- and high-intake rats. Moreover, high-intake rats no longer exhibited augmented reinstatement following $\mathrm{D}_{1}$-like receptor blockade in the NAcc. Reverse dialysis of SCH-23390 is unlikely to have caused motor deficits since operant responding for food was unaltered; although the potency of SCH-23390 to produce motor deficits may have been reduced given that the subjects were drug naive and responding for a natural reinforcer. Instead, $\mathrm{D}_{1}$-like dopamine receptor activation may be necessary for augmented reinstatement in high-intake rats, which would indicate that the sensitized dopaminergic response in the NAcc contributes to heightened relapse vulnerability. In support, infusion of dopamine or a $\mathrm{D}_{1}$-like agonist into the NAcc is sufficient to reinstate drug seeking (Cornish and Kalivas, 2000; Bachtell et al., 2005) (although see Schmidt et al., 2006). Although reinstatement was reduced in our study, $D_{1}$ like receptor antagonism in the NAcc does not completely block 
cocaine-induced reinstatement (Cornish and Kalivas, 2000; Anderson et al., 2003; Bachtell et al., 2005). This may indicate a role for $\mathrm{D}_{2}$-like dopamine receptors or it may support the conclusion that drug-induced plasticity can contribute to heightened relapse vulnerability in high-intake rats even if it is not necessary for reinstatement in low-intake rats.

\section{System $\mathrm{x}_{\mathrm{c}}$ - activity in the NAcc and heightened relapse vulnerability}

Cocaine-induced disruption of system $\mathrm{x}_{\mathrm{c}}$ - in the NAcc may contribute to the sensitized cocaine-induced dopamine response. ${ }^{14} \mathrm{C}$-Cystine uptake by system $\mathrm{x}_{\mathrm{c}}-$ was reduced in NAcc tissue slices obtained from high-intake rats; the cysteine prodrug $\mathrm{N}$-acetyl cysteine blocked the augmented dopamine response observed in high-intake rats. The latter finding may implicate normalization of extracellular dopamine as a potential mechanism whereby $\mathrm{N}$-acetyl cysteine reduces drug craving and use in humans (LaRowe et al., 2006; Mardikian et al., 2007; Knackstedt et al., 2009), and cocaine-induced reinstatement in rats (Baker et al., 2003; Madayag et al., 2007; Kau et al., 2008; Zhou and Kalivas, 2008; Knackstedt et al., 2009). Because nonvesicular release of glutamate by system $\mathrm{x}_{\mathrm{c}}$ - has been shown to activate $\mathrm{mGluR2} / 3 \mathrm{~s}$, which normally function to inhibit synaptic release of glutamate and dopamine (Baskys and Malenka, 1991; Cochilla and Alford, 1998; Hu et al., 1999; Schoepp, 2001; Moran et al., 2005; Morishima et al., 2005; Chaki et al., 2006), it is unclear why reduced cystineglutamate exchange would not also lead to an increase in glutamate. One explanation may be that changes in synaptic glutamate are difficult to detect using standard microdialysis techniques, although microdialysis has been used previously to assess changes in stimulated. A second explanation may be related to the finding that the regulation of extracellular glutamate by $\mathrm{mGluR} 2 / 3 \mathrm{~s}$ in the NAcc is significantly blunted in cocaine-withdrawn subjects (Xi et al., 2002). In the event that reduced mGluR2/3 function is selective for those receptors expressed on glutamate terminals then disruptions in cystine-glutamate exchange in high-intake subjects may preferentially alter extracellular levels of dopamine. Last, blunted system $\mathrm{x}_{\mathrm{c}}-$ and the sensitized cocaine-induced increase in extracellular dopamine observed in high-intake subjects may be unrelated. The tissue used to detect reduced cystineglutamate exchange was obtained from subjects that had not received extinction or reinstatement testing. Additional studies are needed to fully characterize changes in the activity of system $\mathrm{x}_{\mathrm{c}}-$ and mGluR2/3s following high levels of drug intake.

The results of our studies suggest that high levels of drug intake results in the emergence of drug-induced adaptations that contribute to heightened relapse vulnerability. High-intake rats exhibit a more robust increase in extracellular levels of NAcc dopamine, but not glutamate, following a cocaine injection and this likely contributes to the heightened reinstatement observed in these rats. The results are surprising because increased extracellular glutamate, and not dopamine, in the NAcc is necessary for cocaine-induced reinstatement (Cornish and Kalivas, 2000; Park et al., 2002; Anderson et al., 2003; Baker et al., 2003; McFarland et al., 2003; Bachtell et al., 2005; Schmidt et al., 2005; Madayag et al., 2007; Kau et al., 2008). The value of the reinstatement paradigm as a model used to unravel the neurobiology of addiction or as a screen for putative pharmacotherapies depends on the degree to which the subjects express drug-induced plasticity present in human drug abusers (Epstein et al., 2006; Kalivas et al., 2006). The utility of the reinstatement paradigm has been justifiably questioned, in part due to a disconnect between compounds shown to be effective in the model versus the clinic. This study poses the possibility that the lack of predictive validity may be partially resolved by using high-intake conditions that appear to more closely recreate drug-induced changes observed in human drug users. In support, the cysteine prodrug $N$-acetyl cysteine has been shown to be effective in reducing drug seeking in highintake rodents (Baker et al., 2003; Madayag et al., 2007; Kau et al., 2008; Zhou and Kalivas, 2008; Knackstedt et al., 2009) and drug use in human abusers (LaRowe et al., 2006; Mardikian et al., 2007; Knackstedt et al., 2009) as well as drug-induced plasticity in both low- and high-intake subjects.

\section{References}

Ahmed SH, Cador M (2006) Dissociation of psychomotor sensitization from compulsive cocaine consumption. Neuropsychopharmacology 31:563-571.

Ahmed SH, Koob GF (1998) Transition from moderate to excessive drug intake: change in hedonic set point. Science 282:298-300.

Ahmed SH, Walker JR, Koob GF (2000) Persistent increase in the motivation to take heroin in rats with a history of drug escalation. Neuropsychopharmacology 22:413-421.

Ahmed SH, Lin D, Koob GF, Parsons LH (2003) Escalation of cocaine selfadministration does not depend on altered cocaine-induced nucleus accumbens dopamine levels. J Neurochem 86:102-113.

Anderson SM, Bari AA, Pierce RC (2003) Administration of the D1-like dopamine receptor antagonist SCH-23390 into the medial nucleus accumbens shell attenuates cocaine priming-induced reinstatement of drug-seeking behavior in rats. Psychopharmacology (Berl) 168:132-138.

Bachtell RK, Whisler K, Karanian D, SelfDW (2005) Effects of intra-nucleus accumbens shell administration of dopamine agonists and antagonists on cocaine-taking and cocaine-seeking behaviors in the rat. Psychopharmacology (Berl) 183:41-53.

Baker DA, Tran-Nguyen TL, Fuchs RA, Neisewander JL (2001) Influence of individual differences and chronic fluoxetine treatment on cocaineseeking behavior in rats. Psychopharmacology (Berl) 155:18-26.

Baker DA, McFarland K, Lake RW, Shen H, Tang XC, Toda S, Kalivas PW (2003) Neuroadaptations in cystine-glutamate exchange underlie cocaine relapse. Nat Neurosci 6:743-749.

Baskys A, Malenka RC (1991) Agonists at metabotropic glutamate receptors presynaptically inhibit EPSCs in neonatal rat hippocampus. J Physiol 444:687-701.

Chaki S, Yoshikawa R, Okuyama S (2006) Group II metabotropic glutamate receptor-mediated regulation of dopamine release from slices of rat nucleus accumbens. Neurosci Lett 404:182-186.

Cochilla AJ, Alford S (1998) Metabotropic glutamate receptor-mediated control of neurotransmitter release. Neuron 20:1007-1016.

Consolo S, Caltavuturo C, Colli E, Recchia M, Di Chiara G (1999) Different sensitivity of in vivo acetylcholine transmission to $D 1$ receptor stimulation in shell and core of nucleus accumbens. Neuroscience 89:1209-1217.

Cornish JL, Kalivas PW (2000) Glutamate transmission in the nucleus accumbens mediates relapse in cocaine addiction. J Neurosci 20:RC89(1-5).

Cox SM, Benkelfat C, Dagher A, Delaney JS, Durand F, McKenzie SA, Kolivakis T, Casey KF, Leyton M (2009) Striatal dopamine responses to intranasal cocaine self-administration in humans. Biol Psychiatry 65:846-850.

Epstein DH, Preston KL, Stewart J, Shaham Y (2006) Toward a model of drug relapse: an assessment of the validity of the reinstatement procedure. Psychopharmacology (Berl) 189:1-16.

Hu G, Duffy P, Swanson C, Ghasemzadeh MB, Kalivas PW (1999) The regulation of dopamine transmission by metabotropic glutamate receptors. J Pharmacol Exp Ther 289:412-416.

Kalivas PW, Volkow N, Seamans J (2005) Unmanageable motivation in addiction: a pathology in prefrontal-accumbens glutamate transmission. Neuron 45:647-650.

Kalivas PW, Peters J, Knackstedt L (2006) Animal models and brain circuits in drug addiction. Mol Interv 6:339-344.

Kau KS, Madayag A, Mantsch JR, Grier MD, Abdulhameed O, Baker DA (2008) Blunted cystine-glutamate antiporter function in the nucleus accumbens promotes cocaine-induced drug seeking. Neuroscience 155: $530-537$.

Kippin TE, Fuchs RA, See RE (2006) Contributions of prolonged contingent and noncontingent cocaine exposure to enhanced reinstatement of cocaine seeking in rats. Psychopharmacology (Berl) 187:60-67. 
Knackstedt LA, LaRowe S, Mardikian P, Malcolm R, Upadhyaya H, Hedden S, Markou A, Kalivas PW (2009) The role of cystine-glutamate exchange in nicotine dependence in rats and humans. Biol Psychiatry 65:841-845.

Lack CM, Jones SR, Roberts DC (2008) Increased breakpoints on a progressive ratio schedule reinforced by IV cocaine are associated with reduced locomotor activation and reduced dopamine efflux in nucleus accumbens shell in rats. Psychopharmacology (Berl) 195:517-525.

LaRowe SD, Mardikian P, Malcolm R, Myrick H, Kalivas P, McFarland K, Saladin M, McRae A, Brady K (2006) Safety and tolerability of N-acetylcysteine in cocaine-dependent individuals. Am J Addict 15:105-110.

Lenoir M, Ahmed SH (2007) Heroin-induced reinstatement is specific to compulsive heroin use and dissociable from heroin reward and sensitization. Neuropsychopharmacology 32:616-624.

Lobner D, Lipton P (1993) Intracellular calcium levels and calcium fluxes in the CA 1 region of the rat hippocampal slice during in vitro ischemia: relationship to electrophysiological cell damage. J Neurosci 13:48614871.

Madayag A, Lobner D, Kau KS, Mantsch JR, Abdulhameed O, Hearing M, Grier MD, Baker DA (2007) Repeated N-acetylcysteine administration alters plasticity-dependent effects of cocaine. J Neurosci 27:13968-13976.

Mantsch JR, Yuferov V, Mathieu-Kia AM, Ho A, Kreek MJ (2004) Effects of extended access to high versus low cocaine doses on self-administration, cocaine-induced reinstatement and brain mRNA levels in rats. Psychopharmacology (Berl) 175:26-36.

Mantsch JR, Baker DA, Francis DM, Katz ES, Hoks MA, Serge JP (2008) Stressor- and corticotropin releasing factor-induced reinstatement and active stress-related behavioral responses are augmented following longaccess cocaine self-administration by rats. Psychopharmacology (Berl) 195:591-603.

Mardikian PN, LaRowe SD, Hedden S, Kalivas PW, Malcolm RJ (2007) An open-label trial of $\mathrm{N}$-acetylcysteine for the treatment of cocaine dependence: a pilot study. Prog Neuropsychopharmacol Biol Psychiatry 31:389-394.

Martinez D, Narendran R, Foltin RW, Slifstein M, Hwang DR, Broft A, Huang Y, Cooper TB, Fischman MW, Kleber HD, Laruelle M (2007) Amphetamine-induced dopamine release: markedly blunted in cocaine dependence and predictive of the choice to self-administer cocaine. Am J Psychiatry 164:622-629.

McFarland K, Lapish CC, Kalivas PW (2003) Prefrontal glutamate release into the core of the nucleus accumbens mediates cocaine-induced reinstatement of drug-seeking behavior. J Neurosci 23:3531-3537.

Meil WM, See RE (1996) Conditioned cued recovery of responding following prolonged withdrawal from self-administered cocaine in rats: an animal model of relapse. Behav Pharmacol 7:754-763.

Moran MM, McFarland K, Melendez RI, Kalivas PW, Seamans JK (2005) Cystine/glutamate exchange regulates metabotropic glutamate receptor presynaptic inhibition of excitatory transmission and vulnerability to cocaine seeking. J Neurosci 25:6389-6393.

Morishima Y, Miyakawa T, Furuyashiki T, Tanaka Y, Mizuma H, Nakanishi S (2005) Enhanced cocaine responsiveness and impaired motor coordination in metabotropic glutamate receptor subtype 2 knockout mice. Proc Natl Acad Sci U S A 102:4170-4175.

Park WK, Bari AA, Jey AR, Anderson SM, Spealman RD, Rowlett JK, Pierce RC
(2002) Cocaine administered into the medial prefrontal cortex reinstates cocaine-seeking behavior by increasing AMPA receptor-mediated glutamate transmission in the nucleus accumbens. J Neurosci 22:2916-2925.

Paxinos G, Watson C (1986) The rat brain in stereotaxic coordinates. New York: Academic.

Pierce RC, Bell K, Duffy P, Kalivas PW (1996) Repeated cocaine augments excitatory amino acid transmission in the nucleus accumbens only in rats having developed behavioral sensitization. J Neurosci 16:1550-1560.

Reid MS, Berger SP (1996) Evidence for sensitization of cocaine-induced nucleus accumbens glutamate release. Neuroreport 7:1325-1329.

Rogers JL, De Santis S, See RE (2008) Extended methamphetamine selfadministration enhances reinstatement of drug seeking and impairs novel object recognition in rats. Psychopharmacology (Berl) 199:615-624.

Schmidt HD, Anderson SM, Famous KR, Kumaresan V, Pierce RC (2005) Anatomy and pharmacology of cocaine priming-induced reinstatement of drug seeking. Eur J Pharmacol 526:65-76.

Schmidt HD, Anderson SM, Pierce RC (2006) Stimulation of D1-like or D2 dopamine receptors in the shell, but not the core, of the nucleus accumbens reinstates cocaine-seeking behaviour in the rat. Eur J Neurosci 23:219-228.

Schoepp DD (2001) Unveiling the functions of presynaptic metabotropic glutamate receptors in the central nervous system. J Pharmacol Exp Ther 299:12-20.

Shaham Y, Rajabi H, Stewart J (1996) Relapse to heroin-seeking in rats under opioid maintenance: the effects of stress, heroin priming, and withdrawal. J Neurosci 16:1957-1963.

Sorge RE, Stewart J (2005) The contribution of drug history and time since termination of drug taking to footshock stress-induced cocaine seeking in rats. Psychopharmacology (Berl) 183:210-217.

Stewart J (1983) Conditioned and unconditioned drug effects in relapse to opiate and stimulant drug self-adminstration. Prog Neuropsychopharmacol Biol Psychiatry 7:591-597.

Stewart J (2000) Pathways to relapse: the neurobiology of drug- and stressinduced relapse to drug-taking. J Psychiatry Neurosci 25:125-136.

Sutton MA, Karanian DA, Self DW (2000) Factors that determine a propensity for cocaine-seeking behavior during abstinence in rats. Neuropsychopharmacology 22:626-641.

Vanderschuren LJ, Everitt BJ (2004) Drug seeking becomes compulsive after prolonged cocaine self-administration. Science 305:1017-1019.

Volkow ND, Wang GJ, Fowler JS, Logan J, Gatley SJ, Hitzemann R, Chen AD, Dewey SL, Pappas N (1997) Decreased striatal dopaminergic responsiveness in detoxified cocaine-dependent subjects. Nature 386:830-833.

West AR, Grace AA (2002) Opposite influences of endogenous dopamine $D_{1}$ and $D_{2}$ receptor activation on activity states and electrophysiological properties of striatal neurons: studies combining in vivo intracellular recordings and reverse microdialysis. J Neurosci 22:294-304.

Xi ZX, Ramamoorthy S, Baker DA, Shen H, Samuvel DJ, Kalivas PW (2002) Modulation of group II metabotropic glutamate receptor signaling by chronic cocaine. J Pharmacol Exp Ther 303:608-615.

Zhou W, Kalivas PW (2008) N-acetylcysteine reduces extinction responding and induces enduring reductions in cue- and heroin-induced drugseeking. Biol Psychiatry 63:338-340. 